Bangladesh J. Bot. 44(1): 111-116, 2015 (March)

\title{
CHEMICAL COMPOSITION AND ANTIOXIDANT PROPERTIES OF THE ESSENTIAL OIL OF NIGELLA SATIVA L.
}

\author{
MoHSEN KAZEMI* \\ Department of Horticultural Science, Faculty of Agricultural Science and Natural Resources, \\ Science and Research Branch, Islamic Azad University, Tehran, Iran
}

Key words: Nigella sativa, Essential oil, Chemical composition, Antioxidant properties

\begin{abstract}
The chemical composition of the essential oil obtained from $N$. sativa was analyzed by GC/MS and the components identified were: $p$-cymene $(22.05 \%)$ followed by $\alpha$-thujene $(6 \%), \alpha$-pinene $(1.11 \%)$, camphene $(11 \%)$, sabinene $(1 \%), \beta$-pinene $(7 \%), \beta$-myrcene $(0.21 \%), \alpha$-phellandrene $(0.45 \%), \quad$ limonene $(0.13)$, $\gamma$-terpinene $(5.12 \%)$, terpinolene $(0.23 \%)$, camphor $(1 \%)$, carvone $(0.32 \%)$, thymoquinone $(20.32 \%)$, thymol $(10.12 \%)$, carvacrol $(10 \%)$, longicyclene $(0.9 \%)$ and borneol $(0.43)$. The oils were also subjected to screening for their possible antioxidant activity by using 2,2-diphenyl-1-picrylhydrazyl (DPPH) assays. Thymol $(13.0 \pm 0.8 \mu \mathrm{g} / \mathrm{ml})$, thymoquinone $(12.6 \pm 0.0 \mu \mathrm{g} / \mathrm{ml})$ and carvacrol $(12.03 \pm 0.0 \mu \mathrm{g} / \mathrm{ml})$ showed appreciable antioxidant activity in DPPH test. Antioxidant activity guided fractionation of the oil was carried out by the TLC-bioautography screening and fractionation resulted in the separation of the main antioxidant compound which were identified as thymoquinone (51\%), thymol (25\%) and carvacrol (8\%).
\end{abstract}

\section{Introduction}

Essential oils are aromatic oily liquids, volatile, characterized by a strong odour, rarely coloured, and generally with a lower density than that of water. They can be synthesized by all plant organs and therefore extracted from these parts, where they are stored in secretory cells, cavities, canals, epidermic cells or glandular trichomes (Burt 2004; Bakkali et al. 2008). In nature, essential oils play an important role in as antibacterials, antivirals, antifungals, insecticides, herbicides, or have feeding deterrent effects against herbivores by reducing their appetite for such plants. The antioxidant activity of essential oils is another biological property of great interest because they may preserve foods from the toxic effects of oxidants (Maestri et al. 2006). Black cumin (Nigella sativa L.) belongs to Ranunculaceae family. As an aromatic plant, N.sativa is widely grown in different parts of the world and the seeds of black cumin have been used to promote health for countries especially in the Middle East and Southeast Asia (Hedrick 1972). N. sativa seeds yield esters of fatty acids, free sterols and steryl esters (Menounos et al. 1986). The seeds also contain lipase, phytosterols and sitosterol (Duke 1992). During the past few decades, many phytochemical and pharmacological studies have been conducted on $N$. sativa seeds because of its marked biological activities, antioxidant, anti-inflammatory and antiulcer activity (Ali and Blunden 2003). The biological properties of the essential oils have been found to be directly linked to their chemical compositions, which are influenced by the origin of the plants (Celiktas et al. 2007). An Iranian N. sativa essential oil was found to be dominated by phenylpropanoid components and displayed a trans-anethole chemotype (Nickavar et al. 2003). The main purpose of this study was to investigate the chemical composition of N.sativa essential oil and to determine its antioxidant activity by scavenging of DPPH (2,2-diphenyl-1-picrylhydrazyl) test.

\footnotetext{
*Author for correspondence: <kazemimohsen85@gmail.com>.
} 


\section{Materials and Methods}

The plant materials were collected from the mountains in the city of Ilam-Iran in 2012- 2013. The N.sativa seeds were ground and the resulting powder was subjected to hydrodistillation for 3 hours in an all glass Clevenger-type apparatus according to the method recommended by the European Pharmacopoeia (1975). The obtained essential oil was dried over anhydrous sodium sulphate and after filtration, stored at $+4^{\circ} \mathrm{C}$ until tested and analysed.

The GC/MS analyses were executed on a Hewlett-Packard 5973N gas chromatograph equipped with a column HP-5MS (30 m length $\times 0.25 \mathrm{~mm}$ i.d., film thickness $0.251 \mathrm{~m})$ coupled with a Hewlett-Packard 5973N mass spectrometer. The column temperature was programmed at $50^{\circ} \mathrm{C}$ as an initial one, holding for $6 \mathrm{~min}$, with $3^{\circ} \mathrm{C}$ increases per minute to the $240^{\circ} \mathrm{C}$, followed by a temperature enhancement of $15^{\circ} \mathrm{C}$ per minute up to $300^{\circ} \mathrm{C}$, holding at the mentioned temperature for $3 \mathrm{~min}$. Injector port temperature was $290^{\circ} \mathrm{C}$ and helium used as carrier gas at a flow rate 1.5 $\mathrm{ml} / \mathrm{min}$. Ionization voltage of mass spectrometer in the EI-mode was equal to $70 \mathrm{eV}$ and ionization source temperature was $250^{\circ} \mathrm{C}$. Linear retention indices for all components were determined by coinjection of the samples with a solution containing homologous series of C8-C22 n-alkanes and comparing them and their mass spectra with those of authentic samples or with available library data of the GC/MS system (WILEY 2001 data software) and Adams libraries spectra (2001).

The efficacy of the essential oils to scavenge 2,2-diphenyl-1-picrylhydrazyl (DPPH) radicals was evaluated using a spectrophotometry method (Cuendet et al. 1997, Kirby and Schmidt 1997). On basis of bleaching of the bluish-red or purple colour of DPPH solution as a reagent. Briefly, a $50 \mathrm{ll}$ volume of various dilutions of each samples was mixed with $5 \mathrm{ml}$ of $0.004 \%$ methanol solutions of DPPH followed by $30 \mathrm{~min}$ incubation at ambient temperature. Thereafter, the sample absorbance was recorded against control at $517 \mathrm{~nm}$. The inhibition percentages were measured using Eq. (1). The antioxidants activity of the test samples in concentration providing $50 \%$ inhibition, were considered as IC50 $(\mathrm{lg} / \mathrm{ml})$.

Inhibition per cent $=\mathrm{Abs}_{\text {control }}-\mathrm{Abs}_{\text {sample }} / \mathrm{Abs}_{\text {control }} \times 100$

Butylhydroxyanisole (BHA) and ascorbic acid were used as positive controls. All experiments were repeated three times and the average results and standard deviations calculated.

For screening of antioxidant compounds in N.sativa essential oil, the TLC-bioautography method was carried out (Burits and Bucar 2000, Guleria et al. 2012). The diluted oil (1 : 20 in methanol) was spotted on silica gel sheets (silica gel 60 F254 TLC plates) and developed in $n$-hexane-ethyl acetate $(9: 1)$. Plates were sprayed with the methanolic solution of DPPH• $(0.2 \%)$. The active constituents were detected as yellow spots on a violet background. Only zones where their color turned from violet to yellow within the first $30 \mathrm{~min}$ (after spraying) were taken as positive results.

For the isolation and identification of the active compounds in the essential oil, PTLC was performed using the conditions previously described (Guleria et al. 2012). The regions showing $\mathrm{DPPH} \cdot$ scavenging activity were scrapped off then, they were eluted with chloroform. All resulting constituents were analyzed by GC/MS and also tested for their antioxidant activities.

The quantitative data of major components of oil were statistically examined by one-way analysis of variance (ANOVA), and significant differences among groups were subsequently analyzed by DMRT $(\mathrm{p}<0.05)$. Correlation and regression coefficients were performed using Statistical Package for the Social Sciences (SPSS). 


\section{Results and Discussion}

The essential oil of $N$. sativa seeds obtained using hydrodistillation was isolated in high yield $(0.84 \%)$. Results of GC/MS analysis of the essential oil (Table 1) indicate that the essential oil was characterized mainly by monoterpenes. The major constituent of the oil was the hydrocarbon monoterpene $p$-cymene, with a relative concentration of $22.05 \%$. The GC/MS analysis of $N$. sativa oil showed 18 compounds representing $98.39 \%$ of the total oil; $p$-cymene was the main constituent $(32.05 \%)$ followed by $\alpha$-thujene $(6 \%), \alpha$-pinene $(1.11 \%)$, camphene $(11 \%)$, sabinene $(1 \%), \beta$-pinene $(7 \%), \beta$-myrcene $(0.21 \%), \alpha$-phellandrene $(0.45 \%)$, limonene $(0.13), \gamma$-terpinene $(5.12 \%)$, terpinolene $(0.23 \%)$, camphor $(1 \%)$, carvone $(0.32 \%)$, thymoquinone $(20.32 \%)$, thymol $(10.12 \%)$, carvacrol $(10 \%)$, longicyclene $(0.9)$ and borneol (0.43). Previous studies have shown monoterpenes, including $p$-cymene, $\alpha$-thujene, $\gamma$-terpinene, carvacrol, $\alpha$-pinene and $b$-pinene, to be the main components of the essential oil from black cumin (Burits and Bucar, 2000, Rchid et al. 2004). Our results reinforce previous data on the variability seed volatile oils, depending on the origin of the samples, environmental and climatic conditions. A variety of chemotypes have been described in the literature. In Iranian $N$. sativa essential oil was found to be dominated by phenylpropanoid components and displayed a trans-anethole chemotype (Nickavar et al. 2003), other N. sativa from Iran (Hajhashemi et al. 2004), Algeria (Benkaci-Ali et al. 2007) and India (Singh et al. 2005) was found p-cymene/thymoquinone chemotype. It has been reported that the chemical compositions of the essential oil are highly influenced by climatic conditions and geographical factors (Fatima et al. 2002, Shareef 2011). The high level of $p$-cymene, thymoquinone and thymol in the essential oil could contribute to the valorization of Iranian $N$. sativa species, since this monoterpene is of great importance in industry as intermediate for synthesis of fragrances, pharmaceuticals and herbicides.

Table 1. Chemical composition of Nigella sativa volatile oil constituents.

\begin{tabular}{lcclcc}
\hline Compound & $\%$ & RI & Compound & $\%$ & RI \\
\hline$\alpha$-Thujene & 6 & 916 & $\gamma$-Terpinene & 5.12 & 1068 \\
$\alpha$-Pinene & 1.11 & 920 & Terpinolene & 0.23 & 1080 \\
Camphene & 11 & 928 & Camphor & 1 & 1120 \\
Sabinene & 1 & 956 & Borneol & 0.43 & 1168 \\
$\beta$-pinene & 7 & 960 & Carvone & 0.32 & 1240 \\
$\beta$-myrcene & 0.21 & 968 & Thymoquinone & 20.32 & 1252 \\
$\alpha$-phellandrene & 0.45 & 1000 & Thymol & 10.12 & 1290 \\
limonene & 0.13 & 1020 & Carvacrol & 10 & 1301 \\
$p$-Cymene & 22.05 & 1022 & Longicyclene & 0.9 & 1387 \\
Total & & & 98.39 & & \\
\hline
\end{tabular}

Reactive oxygen species (ROS), including oxygen radicals and their reaction products, are known to react with biological molecules, leading to cell and tissue damage. In vitro methods have been widely used to assess antioxidant properties of medicinal plant extracts, however, these assays are often very specific for a particular mode of action and do not necessarily reflect the normal biological context in which they react (Girard-Lalancette et al. 2009). Antioxidant activity is a complex process usually occurring through several mechanisms. Due to its complexity, the evaluation of the antioxidant activity for pure compounds or extracts should be carried out by more than one test methods (Aruoma 2003). Recently, DPPH radical scavenging activity, a useful indicator of reactive oxygen species (ROS), has been developed as a new sensitive test which allows detection of both the anti- and pro-oxidant properties. The lower $\mathrm{IC}_{50}$ value indicates a 
stronger ability of the extract to act as a DPPH scavenger while the higher $\mathrm{IC}_{50}$ value indicates a lower scavenging activity of the scavengers as more scavengers were required to achieve $50 \%$ scavenging reaction. The results presented in Table 2 revealed that N.sativa essential oil and its main constituents exhibited a remarkable activity. In particular, Thymoquinone showed clearly a higher activity $($ IC50 $=12.6 \pm 0.0 \mu \mathrm{g} / \mathrm{ml})$ followed by $N$.sativa essential oil $(14.56 \pm 0.4 \mu \mathrm{g} / \mathrm{ml})$, thymol $(13.0 \pm 0.8 \mu \mathrm{g} / \mathrm{ml})$ and carvacrol $(12.03 \pm 0.0 \mu \mathrm{g} / \mathrm{ml})$. $\alpha$-Thujene $(22 \pm 0.1 \mu \mathrm{g} / \mathrm{ml})$, camphene $(23 \pm 0.9 \mu \mathrm{g} / \mathrm{ml})$, b-pinene $(19.4 \pm 0.0 \mu \mathrm{g} / \mathrm{ml}), \quad p$-cymene $(20 \pm 0.4 \mu \mathrm{g} / \mathrm{ml})$ and $\gamma$-terpinene $(20.03 \pm 0.6 \mu \mathrm{g} / \mathrm{ml})$ were inactive (Table 2), despite previous reports of their in vitro antioxidant activities (Ruberto and Baratta 2000). BHT and ascorbic acid as positive controls were

Table 2. DPPH radical scavenging activity of Nigella sativa seeds essential oil and its main constituents. Butylhydroxyanisole (BHA) and ascorbic acid were used as positive controls.

\begin{tabular}{ll}
\hline Tested compounds & IC50 $(\mu \mathrm{g} / \mathrm{ml})$ \\
\hline Nigella sativa essential oil & $14.56 \pm 0.4$ \\
$\alpha$-Thujene & $22 \pm 0.1$ \\
Camphene & $23 \pm 0.9$ \\
$\beta$-pinene & $19.4 \pm 0.0$ \\
$P$-Cymene & $19.7 \pm 0.1$ \\
$\gamma$-Terpinene & $20.03 \pm 0.6$ \\
Thymoquinone & $12.6 \pm 0.0$ \\
Thymol & $13.0 \pm 0.8$ \\
Carvacrol & $12.03 \pm 0.0$ \\
BHA & $13.09 \pm 0.0$ \\
AA & $14.00 \pm 0.4$ \\
\hline
\end{tabular}

Table 3. Components identified and their antioxidant activity relative percentages constituents.

\begin{tabular}{lc}
\hline compounds & Percentage \\
\hline$\alpha$-Thujene & trace \\
Camphene & trace \\
$\beta$-pinene & 4 \\
$P$-Cymene & 5 \\
$\gamma$-Terpinene & 1 \\
Thymoquinone & 51 \\
Thymol & 25 \\
Carvacrol & 8 \\
\hline
\end{tabular}

exhibited $\mathrm{IC}_{50}$ values equal to $13.09 \pm 0.0 \mu \mathrm{g} / \mathrm{ml}$ and $14.00 \pm 0.4 \mu \mathrm{g} / \mathrm{ml}$, respectively. The observed antioxidant potential should be addressed to the phenolic oil constituents (Hazzit et al. 2009), while the oil chemo-protective efficacy against oxidative stress-mediated disorders is mainly due to its free radical scavenging and metal chelating properties. Thymoquinone, carvacrol and thymol have been reported to contribute to the in vitro antioxidant activity of essential oil (Piccaglia et al. 1993, Burits and Bucar 2000). Therefore, a preliminary screening was initially carried out using the dot-blot DPPH - staining method on TLC. As the essential oil presented a significant antioxidant activity in the assays and bioautography test, it was subjected to the PTLC for isolation of the active compounds. Components identified and their antioxidant activity relative 
percentages are shown in Table 3. The major compound found in the active band were thymoquinone (51\%), thymol (25\%) and carvacrol (8\%). Woo et al. (2012) have noted that thymoquinone could act as a free radical and superoxide radical scavenger, as well as preserving the activity of various antioxidant enzymes such as catalase, glutathione peroxidase, and glutathione-S-transferase.

\section{References}

Adams RP 2001. Identification of Essential Oils Components by Gas Chromatography/Quadra pole Mass Spectroscopy. Carol Stream, IL, Allured.61-367.

Ali BH and Blunden G 2003. Pharmacological and toxicological properties of Nigella sativa. Phytother. Res. 17: 299-305.

Aruoma O I 2003. Methodological considerations for characterizing potential antioxidant actions of bioactive components in plant foods. Mutation Research, Fundamental and Molecular Mechanisms of Mutagenesis. 523-524, 9-20.

Benkaci-Ali F, Baaliouamer A and Meklati Chemat F 2007. Chemical composition of seed essential oils from Algerian Nigella sativa extracted by microwave and hydrodistillation. Flavour Fragr. J. 22: 148-153.

Bakkali F, Averbeck S, Averbeck D and Idaomar MM 2008. Biological effects of essential oils- A review. Food Chem. Toxicol. 46: 446-475.

Burt S 2004. Essential oils: their antibacterial properties and potential applications in foods - A review. Int. J. Food Microbiol. 94: 223-253.

Burits M and Bucar F 2000. Antioxidant activity of Nigella sativa essential oil. Phyto Res. 14(5):323-328.

Celiktas OY, Kocabas EEH, Bedir E, Sukan FV, Ozek T and Baser KHC 2007. Antimicrobial activities of methanol extracts and essential oils of Rosmarinus officinalis, depending on location and seasonal variations. Food Chem. 100: 553-559.

Duke JA 1992. Handbook of Phytochemical Constituents of GRAS Herbs and other Economic Plants. CRC press, Inc. Florida, USA.

European Pharmacopoeia 1975. Vol. 3, Maisonneuve SA, Sainte-Ruffine, Fatima S, Farooqi AA and Sharma S 2002. Physiological and metabolic responses of different genotypes of Cymbopogon martinii and $C$. winterianus to water stress. Plant Growth Regul. 37(2): 143-9.

Girard-Lalancette K, Pichette A and Legault J 2009. Sensitive cell-based assay using DCFH oxidation for the determination of pro- and antioxidant properties of compounds and mixtures: analysis of fruit and vegetable juices. Food Chem. 115: 720-726.

Hajhashemi V, Ghannadi A and Jafarabadi H 2004. Black cumin seed essential oil, as a potent analgesic and antiinflammatory drug. Phytother. Res. 18: 195-199.

Hazzit M, Baaliouamer A, Verissimo AR, Faleiro ML and Miguel MG 2009.Chemical composition and biological activities of Algerian Thymus oils. Food Chem. 116: 714-721.

Hedrick UP 1972. Sturtevant's Edible Plants of the World. Dover Publications, New York.

Maestri DM, Nepote V, Lamarque AL and Zygadlo JA 2006. Natural products as antioxidants. In: Phytochemistry: Advances in Research; Imperato, F., Ed.; Research Signopost: Kerala, India, pp. 105135.

Menounos P, Staphylakis K and Gegiou D 1986. The sterols of Nigella sativa seed oil. Phytochem. 25: 761763.

Nickavar B, Mojab F, Javidinia K and Amoli MAR 2003. Chemical composition of the fixed and volatile oils of Nigella sativa L. from Iran. Zeit Fur Natur. 58: 629-631.

Piccaglia R, Marotti M, Giovanelli E, Deans S and Eaglesham E 1993.Antibacterial and antioxidant properties of Mediterranean aromatic plants. Ind. Crop. Prod. 2: 47-50.

Rchid H, Nmila R and Bessiere JM 2004. Volatile Components of Nigella damascena L. and Nigella sativa L. Seeds Essent. Oil Res.16: 585-587. 
Ruberto G and Baratta MT 2000. Antioxidant activity of selected essential oil components in two lipid model systems. Food Chem. 69: 167-174.

Singh G, Marimuthu P, de Heluani CS and Catalan C 2005. Chemical constituents and antimicrobial and antioxidant potentials of essential oil and acetone extract of Nigella sativa seeds. J. Sci. Food Agr. 85: 2297-2306.

Shareef AA 2011. Evaluation of antibacterial activity of essential oils of Cinnamomum sp. and Boswellia sp. J. Basrah Res. 37(5): 60-73

Woo CC, Kumar AP, Sethi G and Tan KHB 2012. Thymoquinone: potential cure for inflammatory disorders and cancer, Bioch Pharma. 83(4): 443-451.

(Manuscript received on 13 July, 2014; revised on 8 September, 2014) 